\title{
Synthesis of silver nanoparticles using wild Cucumis anguria: Characterization and antibacterial activity
}

\author{
Muchanyereyi-Mukaratirwa Netai ${ }^{1}$, Moyo Joyce N. ${ }^{1}$, Nyoni Stephen ${ }^{1,2^{\star}}$ and Cexton Musekiwa ${ }^{1}$ \\ ${ }^{1}$ Chemistry Department, Bindura University of Science Education, Bindura, Zimbabwe. \\ ${ }^{2}$ Chemistry Department, Chinhoyi University of Technology, Chinhoyi, Zimbabwe.
}

Received 18 May, 2017; Accepted 1 September, 2017

\begin{abstract}
In the present study silver nanoparticles were synthesized using wild Cucumis anguria leaf extract using the green route which is a simple, cost-effective and an environmentally friendly technique. When the aqueous silver ions were exposed to the wild $C$. anguria leaf extract, they were reduced and this resulted in the formation of silver nanoparticles. The conditions of synthesis were optimized by adjusting the $\mathrm{pH}$, time and amount of leaf extract. The synthesized silver nanoparticles were characterized by different techniques, namely ultra-violet visible spectroscopy, Fourier Transform Infrared Spectroscopy, X-ray diffraction and transmission electron microscopy. The ultra violet-visible spectrum of the synthesized silver nanoparticles shows a maximum peak at $420 \mathrm{~nm}$. Fourier transform infrared spectroscopy results show the presence of alcohols, aromatics and amines suggesting the presence and binding of proteins with silver nanoparticles. Transmission electron microscopy analysis shows that the silver nanoparticles synthesized were spherical in shape with their sizes ranging between 11 and $27 \mathrm{~nm}$ depending on the $\mathrm{pH}$ conditions. X-ray diffraction analysis results show the presence of silver metal nanoparticles and their crystalline nature. The antibacterial activity of the silver nanoparticles synthesized was evaluated against Staphylococcus aureus (Gram-positive) and Escherichia coli (Gram-negative) bacterial and kanamycin was used as a control. The green chemistry route has proven that silver nanoparticles can be synthesized using $C$. anguria leaf extract in which biomolecules effectively act as reducing and capping agents.
\end{abstract}

Key words: Silver nanoparticles, green synthesis, Cucumis anguria, antibacterial activity.

\section{INTRODUCTION}

Nanotechnology is an important scientific field which deals with the production, manipulation and use of materials in the nano range. It deals with all the processes that take place on the nanometer scale that is from approximately 1 to $100 \mathrm{~nm}$ (Duncan, 2011; Ahmed et al., 2016). The synthesis of nanoparticles has recently gained interest due to their wide variety of applications in areas such as medicine, catalysis, electronics, photonics, computer transistors, sensing, antimicrobial activity, antiinflamatory and so on (Jeong et al., 2005; Moon et al.,

*Corresponding author. E-mail: nyonistephen@yahoo.com, snyoni@cut.ac.zw.

Author(s) agree that this article remains permanently open access under the terms of the Creative Commons Attribution License 4.0 International License 


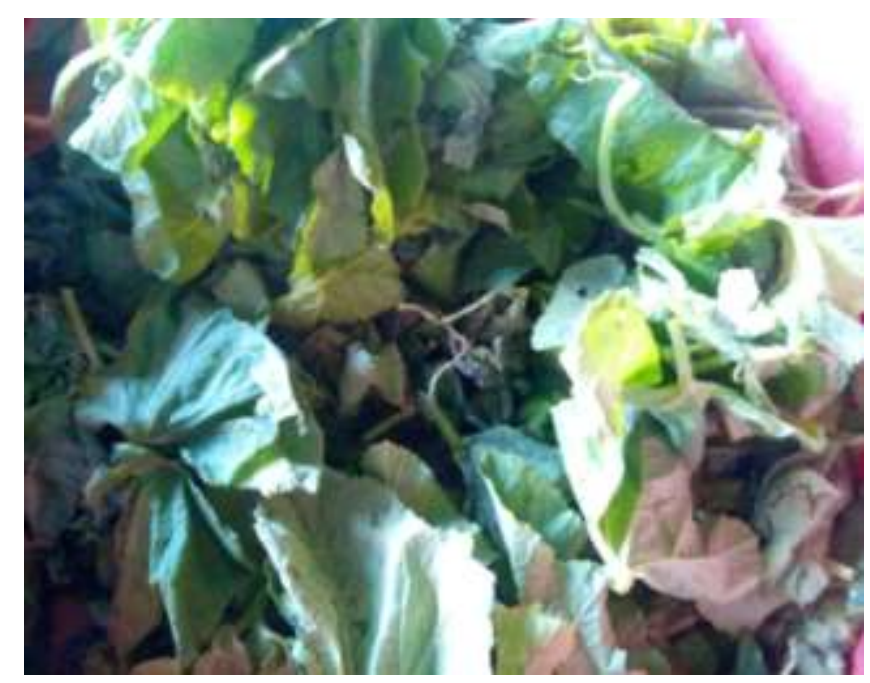

Figure 1. Leaves of wild Cucumis anguria.

2005; Lee and El-Sayed, 2006; Gong et al., 2007; Alexander, 2009; Chen et al., 2009; Gopinath et al., 2012; Mukherjee et al., 2002). Most of these desirable characteristics of the nanoparticles are attributed to their extremely small size and large surface volume compared to their bulk counterparts. Nanoparticles possess size and shape (cylinders, rods, spheres etc) dependent properties which are of interest for such applications (Narayanan, 2012; Roy and Das, 2015). Silver and gold nanoparticles have been particularly used with promising results as bactericides and anticancer agents (Xu et al., 2006; Devara et al., 2013).

Nanomaterials can be made of different materials and the common materials include silicates, metal oxides, non-oxide organics, ceramic polymers, metals, carbon and bio-molecules (Nagarajan, 2008). Basically there are two main groups into which nanoparticles can be classified, that is, organic and inorganic.

Various methods have been used for synthesizing silver nanoparticles and these methods include the chemical, physical and biological methods (Chandran et al., 2006; Jha et al., 2009; Raghunandan et al., 2010; Iravani, 2011; Jacob et al., 2011; Zayed et al., 2012; Kumarasamyraja and Jeganathan, 2013; Suman et al., 2013; Rodriguez-Leon et al., 2013; Roy et al., 2015). Most chemical methods used for synthesizing nanoparticles are too expensive and time consuming and at the same time the intense use of solvents and synthetic reactants is toxic and hazardous to the environment. This has led to the green methods of nanomaterial preparation which involve a single step and involve the use of environmentally friendly reactants. Silver nanoparticles obtained by the green synthesis methods provide good candidates to be used in biological systems. The green synthesis route requires two elements for nanoparticle growth: a silver salt and a reducing agent.
It has been revealed that some bacterial strains have developed resistance against common drugs (Singh et al., 2014). This resistance to medication by disease causing organisms has caused a stir in the medicine industry and this has led to the need to develop new bactericides and virucides. Silver and silver nanoparticles have an antiseptic and disinfectant history and are able to interact with disulphide bonds of the glycoprotein/protein contents of microorganisms (Ahmed et al., 2016). The resistance to medication by pathogens has become a stern concern in public health (Singh et al. 2014), hence the need for synthesis of silver nanoparticles. The synthesized nanoparticles should be more compatible for medical applications hence the use of edible plant extracts. Therefore, the exploitation of plant extracts has materialized as a novel method for the synthesis of silver nanoparticles (Shahverdi et al., 2007). In this work Cucumis anguria (Gherkin), a medicinal vegetable crop was selected which is abundantly found in Zimbabwe, and has a great potential for commercial reproduction for sustainable green synthesis of AgNPs. Figure 1 shows the leaves from $C$. anguria.

Analysis of the phytochemicals found in wild $C$. anguria leaves revealed that the leaves contain very useful compounds such as flavonoids, tannins, alkaloids, saponins and steroids which possess high levels of antioxidant activity (Dzomba and Mupa, 2012). Anthraquinones and saponins present in wild $C$. anguria exhibit antibacterial and antifungal activity against most clinical pathogens. However the leaves of wild C. anguria have not been reported for the synthesis of silver nanoparticles. In view of this background this plant is chosen as a reducing and stabilizing agent for the green synthesis of silver nanoparticles as well as their characterization and application in therapeutics.

\section{MATERIALS AND METHODS}

\section{Preparation of the leaf extract}

The leaves of wild $C$. anguria were collected from the local area of Chiweshe, Zimbabwe (from ARDA and Visa farms) and were thoroughly washed 4 to 5 times using distilled water to remove any dust particles and any other contaminating particles. About $30 \mathrm{~g}$ of fresh leaves were finely chopped and placed in a heating container and about $90 \mathrm{ml}$ of reagent grade water was added. The mixture was boiled for $1 \mathrm{~h}$ while stirring continuously. After boiling, the mixture was cooled and filtered using a vacuum pump with a Whatman paper number 1 and the filtrate was collected.

\section{Synthesis of silver nanoparticles}

About $1 \mathrm{mM}$ of aqueous solution of silver nitrate was prepared and used for the synthesis of silver nanoparticles. $10 \mathrm{ml}$ of the wild $C$. anguria leaf extract was treated with $90 \mathrm{ml}$ of $1 \mathrm{mM}$ silver nitrate solution for bio-reduction process at room temperature under static conditions. The resulting solution was incubated in the dark (to minimize the photo activation of silver nitrate). The process of synthesizing silver nanoparticles was repeated at different $\mathrm{pH}(4,7$, 
9 and 11) and also at different concentrations of leaf extract by reacting different amounts $(1,2,3$ and $4 \mathrm{ml})$ of the $C$. anguria leaf extract with $10 \mathrm{ml}$ of $1 \mathrm{mM} \mathrm{AgNO}$ solution. The silver nanoparticles formed were centrifuged at $2000 \mathrm{rpm}$ for $10 \mathrm{~min}$ and the supernatant was decanted. The resulting suspension was redispersed in $10 \mathrm{ml}$ sterile distilled water and the centrifugation process was repeated for three times to purify the synthesized silver nanoparticles.

\section{Characterizing the synthesized silver nanoparticles}

\section{Ultra violet-visible analysis}

The biosynthesis of silver nanoparticles was monitored using a GENESYS 10S (Thermo Fisher Scientific, UK) UV-Vis spectrophotometer at the wave length range of 200 to $800 \mathrm{~nm}$ at different times of synthesis (after 1, 12, 24 and $48 \mathrm{~h}$ ).The scanning was repeated using silver nanoparticles synthesized at different $\mathrm{pH}$ $(4,7,9$ and 11) and silver nanoparticles synthesized at different leaf extract concentrations (1l, 2, 3 and $4 \mathrm{ml}$ ). Distilled water was used as a blank.

\section{Fourier transform infrared analysis}

FTIR analysis was carried out to identify the various functional groups in biomolecules responsible for the bio-reduction of $\mathrm{Ag}^{+}$ions and capping/stabilization of silver nanoparticles. The analysis was done using a NIOLET iS5 (Fisher Thermo Scientific, UK) FTIR spectrometer. About $20 \mathrm{ml}$ of wild $C$. anguria leaf extract and $20 \mathrm{ml}$ of the synthesized silver nanoparticles were air dried at room temperature. The dried powder samples of the leaf extract and silver nanoparticles were analyzed in the range of 400 to $4000 \mathrm{~cm}^{-1}$ at a resolution of $4 \mathrm{~cm}^{-1}$.

\section{Transmission electron microscopy analysis}

The Joel JEM-2100 (Akishima-Shi, Japan) transition electron microscope was used to determine the size and shape of the synthesized silver nanoparticles. Sample preparation was done by dissolving about $10 \mathrm{mg}$ of silver nanoparticles in ethanol to form a suspension. The suspension was ultrasonicated for formation of a uniform suspension of silver nanoparticles in ethanol. The suspension was then centrifuged and the supernatant was collected. A very low concentration of the supernatant was dropped on the TEM carbon coated copper grid mesh and it was allowed to dry. The dry silver nanoparticles on a carbon coated copper grid mesh were then screened and images were collected.

\section{$X$-ray diffraction analysis}

Sample preparation was done by grinding the silver nanoparticles into a fine powder and placing it on a sample holder. Screening was done using X'PERT-PROGoniometer (PANalytical, Japan) operating at a voltage of $40 \mathrm{kv}$ and current of $40 \mathrm{~mA}$ with a Cu ka radiation. The scanning mode used was continuous with a scanning range $(2 \theta)$ from around $4^{\circ}$ to approximately $90^{\circ}$. The images obtained were compared with the Joint Committee on Powder Diffraction Standards (JCPDS) library to account for the crystalline structure.

Evaluation of antibacterial activity of the synthesized silver nanoparticles

The disc diffusion method was used in the procedure for evaluation of the antibacterial activity of the synthesized silver nanoparticles (Malabadi et al., 2005). Antibacterial activity of $C$. anguria silver nanoparticles was evaluated against both Gram-positive (Staphylococcus aureus) and Gram-negative (Escherichia coli) pathogenic microorganisms. In brief, Mueller Hinton (MH) agar base plates were prepared using sterile $90 \mathrm{~mm}$ Petri dishes. $\mathrm{MH}$ agar was inoculated with $\mathrm{MH}$ broth culture of each bacterial species and poured over the base plates to form a homogenous layer. Filter paper discs ( $5 \mathrm{~mm}$ in diameter) were sterilized and the sterile paper discs were dipped in silver nanoparticle solution $(10 \mu \mathrm{g} / \mathrm{ml})$; some were placed in silver nitrate solution and some sterile discs were dipped in $C$. anguria leaf extract. These discs were then air dried under sterile conditions. The dry sterile discs were then placed onto the seeded top layer of the $\mathrm{MH}$ agar plates and were left for $30 \mathrm{~min}$ at room temperature for compound diffusion. Kanamycin was used as positive control. Plates were incubated for $24 \mathrm{~h}$ at $37^{\circ} \mathrm{C}$ and the zones of inhibition were measured and recorded in millimeters.

\section{RESULTS AND DISCUSSION}

$\begin{aligned} & \text { Characterization of the synthesized silver } \\ & \text { nanoparticles }\end{aligned}$

\section{Visual observation}

Visual observation was used to confirm the formation of silver nanoparticles. The yellow mixture of silver nitrate and $C$. anguria turned to a dark brown colour indicating the formation of silver nanoparticles. The colour changes in the formation of silver nanoparticles are shown in Figure 2.

This characteristic brown color of silver nanoparticles provided simple spectroscopic signature to indicate the formation of nanoparticles (Prasad et al., 2011). The formation of silver nanoparticles occurred from a few minutes to hours agreeing with reports for other plant extracts (Chanda, 2014). It was noted through visual observation that silver nanoparticle formation was rapid (as was shown by a rapid colour change) under neutral and basic conditions and this could be due to the ionization of the phenolic group present in the $C$. anguria leaf extract (Martinez-Castanon et al., 2008). The rate was noted to be slow under acidic conditions, and this can be attributed to the electrostatic repulsion of the anions present in solution (Sun et al., 2014). At basic pH there is a possibility of $\mathrm{Ag}^{+}$ions precipitating as $\mathrm{AgOH}$.

\section{Ultra violet-visible analysis}

UV-Vis spectroscopic curves presented in Figures 2 to 4 show peaks around $425 \mathrm{~nm}$. This confirms the formation of silver nanoparticles (Shankar et al., 2004). The absorption spectrum noted around $425 \mathrm{~nm}$ could have originated from the strong Surface Plasmon Resonance (SPR) that is due to resonant absorption of photons by silver nanoparticles (Kokila et al., 2015). Figure 3 shows that the intensity of absorption increases with time indicating the enhancement of silver nanoparticle formation with time as a result of reduction of $\mathrm{Ag}^{+}$ions 
A

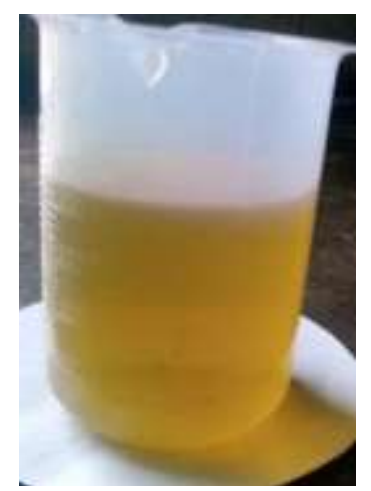

B

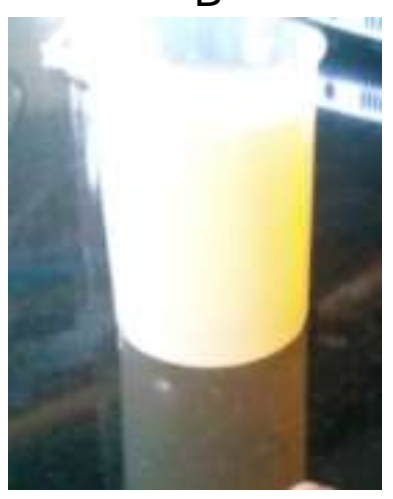

C

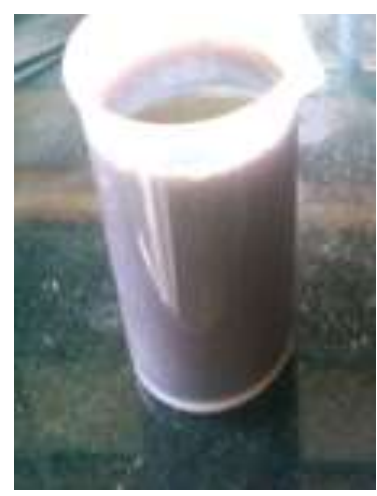

Figure 2. Colour change upon silver nanoparticle formation. (A) The colour of the leaf extract. (B) The colour of the reaction mixture at the beginning. (C) The color of the solution after $48 \mathrm{~h}$ of reaction.
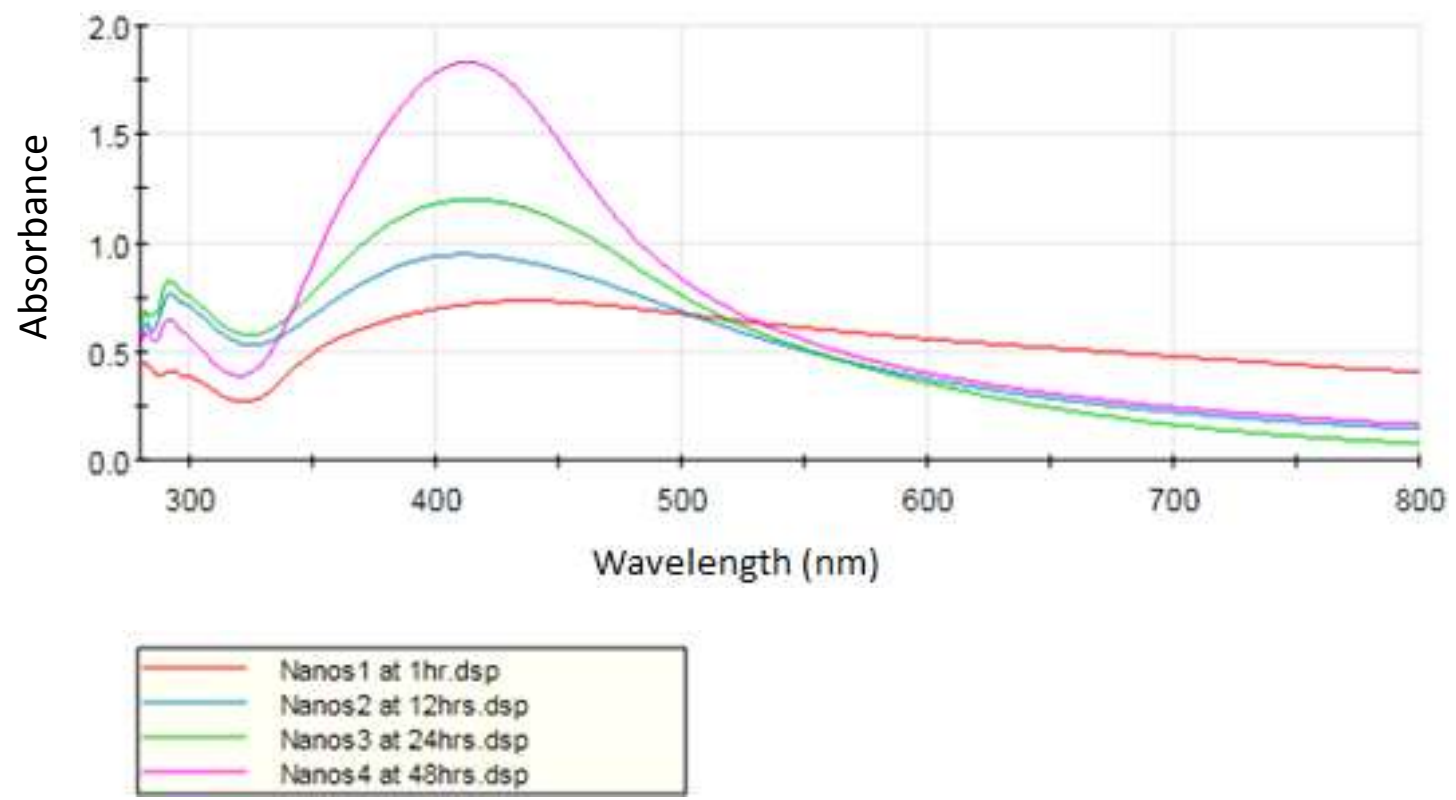

Figure 3. Absorption spectra of $\mathrm{AgNPs}$ (synthesized from $1 \mathrm{mM} \mathrm{AgNO}$ and Cucumis anguria leaf extract) observed at four different times. The figure shows an increase of absorption intensity as a function of reaction time.

with the help of reducing agents present in the $C$. anguria leaf extract. $C$. anguria leaf extract possess natural reducing agents like flavonoids and terpenoids and saponins which are responsible for the reduction of silver ions to silver nanoparticles. The intensity of the SPR band increased without any shift in the peak wavelength with passage of time. This can be attributed to minimum polydispersion of the synthesized nanoparticles. Similar results were obtained when silver nanoparticles were synthesized from Lippia javanica (Kumar et al., 2015) implying that stabilizing molecules or functional groups from the two plants could be the same, or the size and shape of the synthesized nanoparticles at the specified conditions were the same.

UV-Vis analysis was also done for the silver nanoparticles synthesized at different $\mathrm{pH}$ and the nanoparticles at different $\mathrm{pH}$ were given maximum formation time before scanning them under UV-vis. The results are shown in Figure 3.

The results in Figure 4 show that fewer nanoparticles were formed under acidic conditions and the number of silver nanoparticles increased with an increase in $\mathrm{pH}$ as shown by an increase in intensity as the $\mathrm{pH}$ increased. The maximum formation of silver nanoparticles occurred 

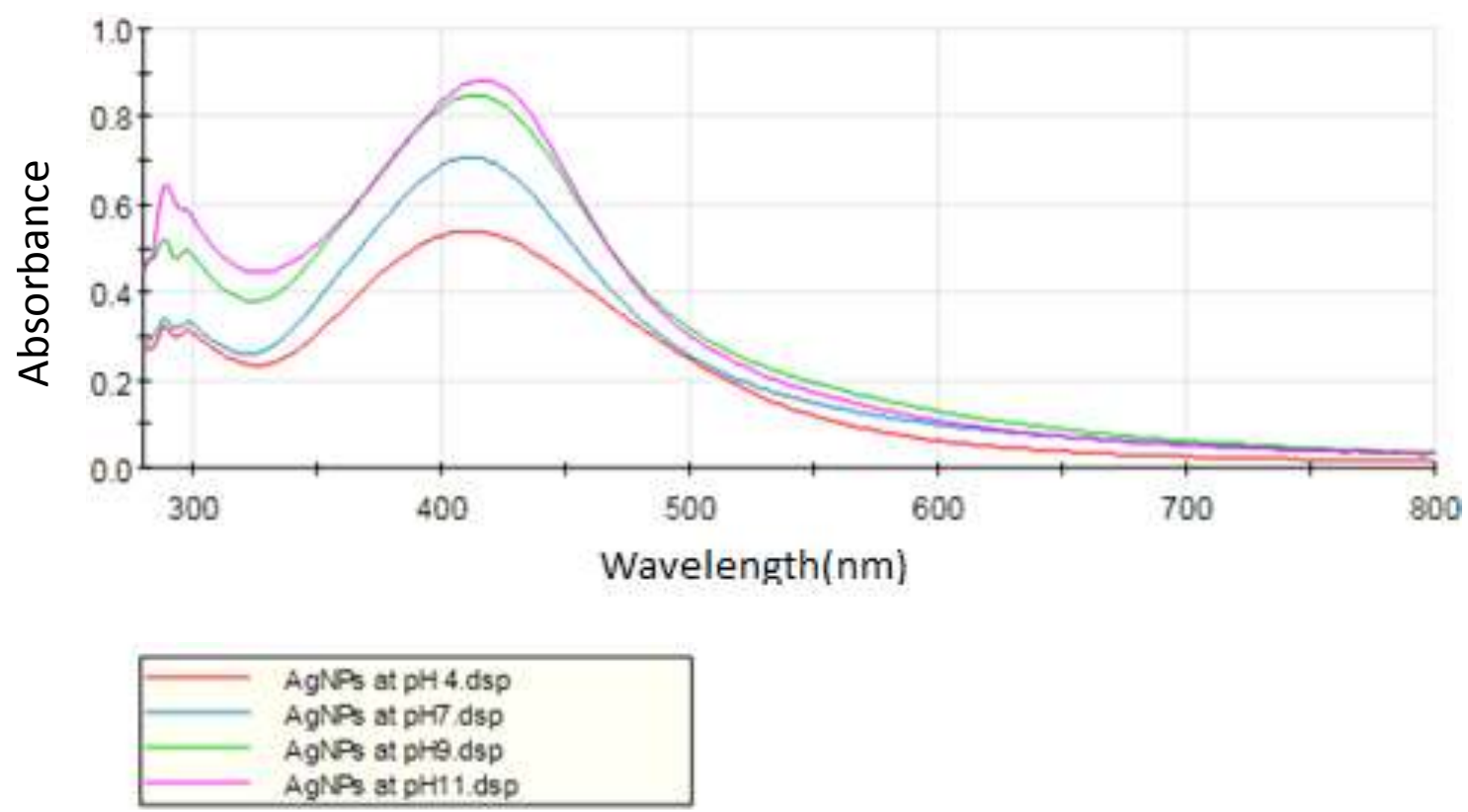

Figure 4. Absorption spectra of AgNPS (synthesized from $1 \mathrm{mM} \mathrm{AgNO}_{3}$ and $C$. anguria leaf extract) at different $\mathrm{pH}$ values $(\mathrm{pH}=4,7,9$ and 11$)$.
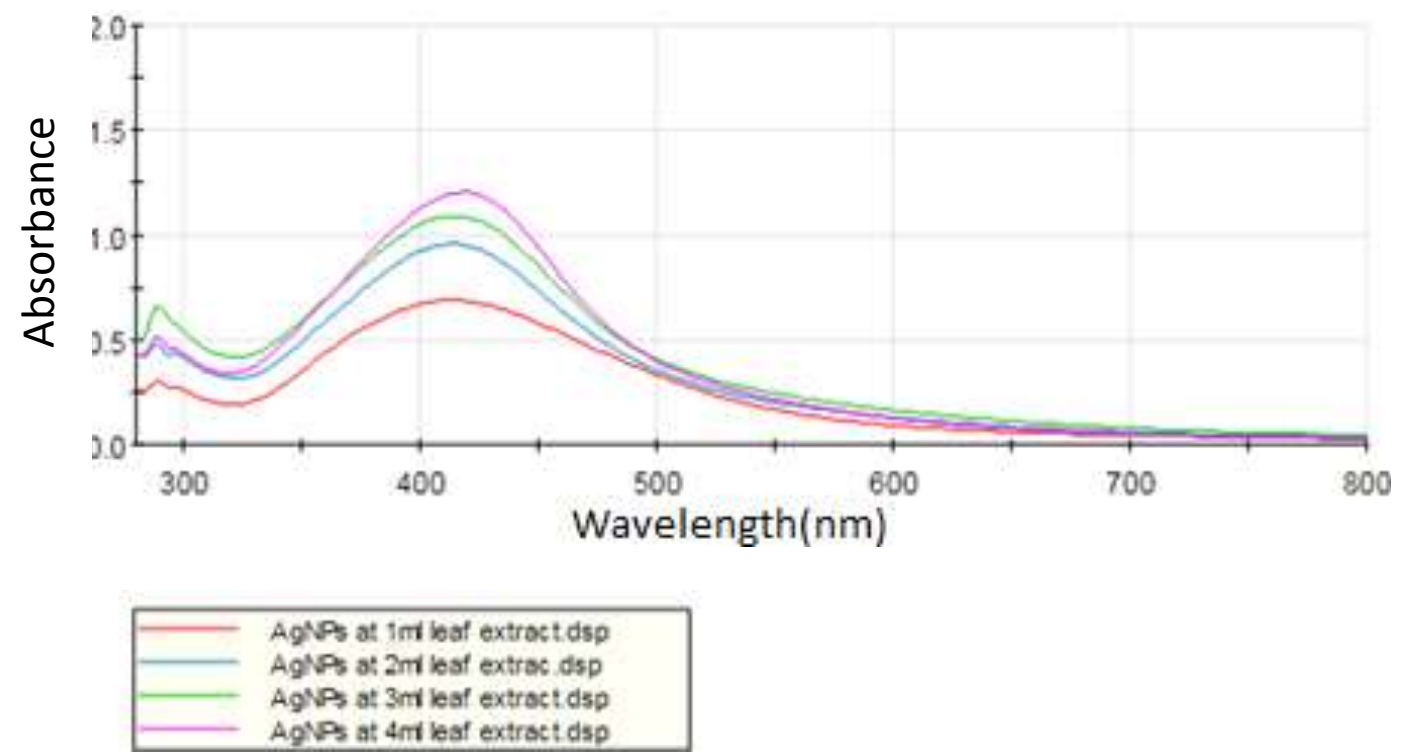

Figure 5. Absorption spectra of AgNPs of different amounts of $C$. anguria leaf extract (1, 2, 3 and $4 \mathrm{ml})$ with 10 of $1 \mathrm{~m} \mathrm{MAgNO}_{3}$ solution. The figure shows an increase of absorption intensity with an increase in the amount of leaf extract.

at $\mathrm{pH}$ 11. Higher SPR intensity at alkaline conditions depicts increased number of smaller silver nanoparticles (Kokila et al., 2015). Alkaline conditions favour the formation of silver nanoparticles because hydroxides get deposited on the silver nanoparticles (Oza et al., 2013). At alkaline $\mathrm{pH}$, both reducing and the capping agents are efficiently reducing the silver. Also, they promote encapping of nanoparticles making them thermodynamically favorable. Figure 5 shows that an increase in the concentration of $C$. anguria leaf extract leads to an increase in the peak intensity indicating an enhancement in the production of silver nanoparticles as the concentration of leaf extract increases.

Similar results were obtained when silver nanoparticles 


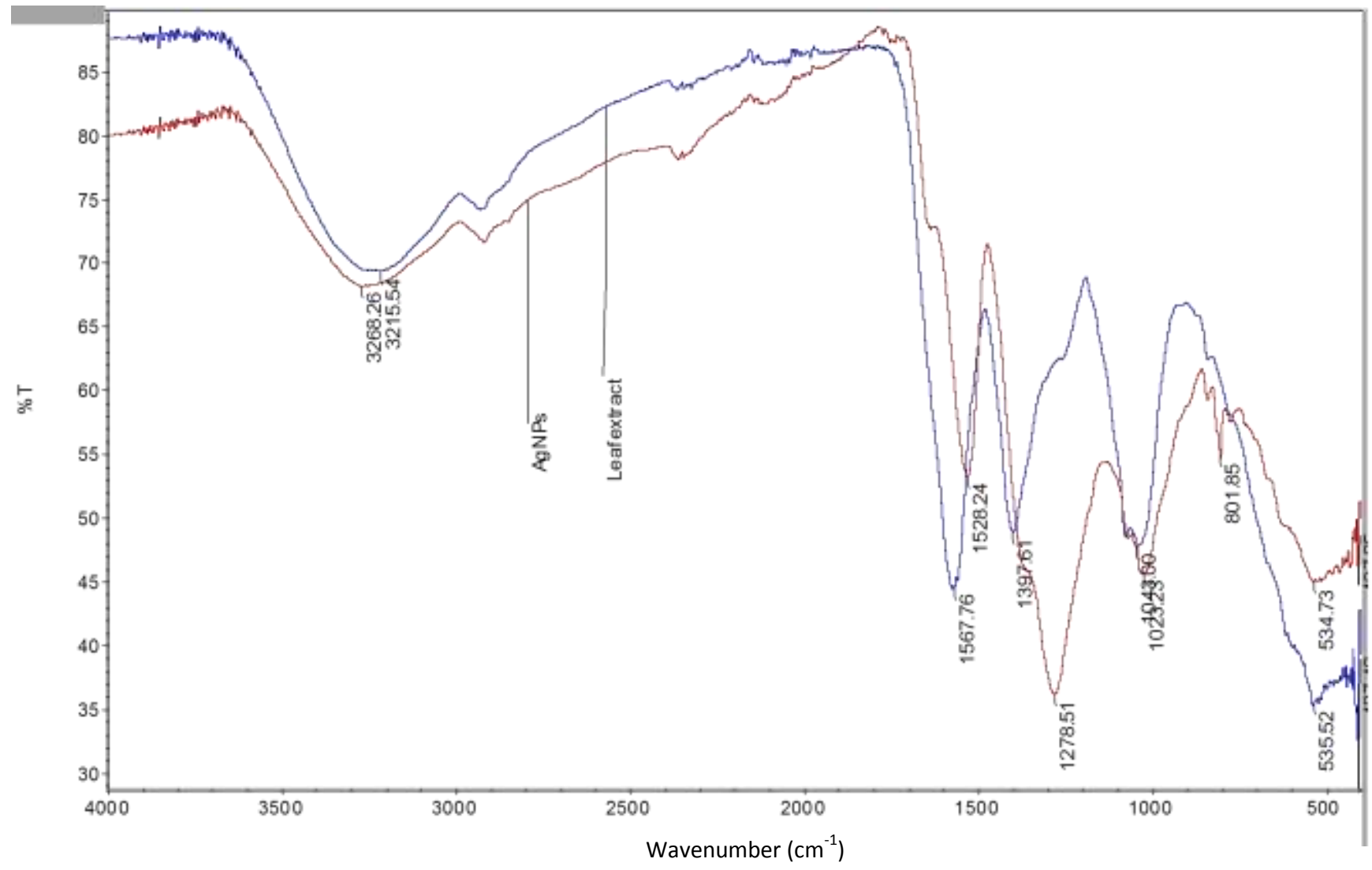

Figure 6. Combined FTIR spectra of AgNPs and C. anguria leaf extract.

were synthesized using Ficus Benghalensis leaf extract (Saware et al., 2014). All UV-Vis results show that the silver nanoparticles synthesized are spherical in shape. According to Mies theory (He et al., 2002; Kokila et al., 2015), only a single SRP band is expected in the absorption spectra of spherical metal nanoparticles whereas anisotropic nanoparticles give rise to two or more SPR bands depending on the shape of the nanoparticles. In the present study a single SPR peak was formed which suggest that the nanoparticles synthesized were spherical in shape. The broadened peaks shown by the UV-Vis results indicate that the particles were poly-dispersed (Maria et al., 2015).

\section{Fourier transform infrared analysis}

FTIR analysis was done for both the dried silver nano particles and the dried $C$. anguria leaf extract. The FTIR spectroscopic studies were performed to investigate interaction between the surface of silver nanoparticles and possible organic functional groups of constituent compounds present in the leaf extract. The band intensities in the different regions of the spectrum of $\mathrm{C}$. anguria leaf extract and silver nanoparticles are shown in
Figure 6.

The spectrum of the leaf extract shows bands at $3215.54,1567.76,1397.61,1043.23,801.20,535.52$ and $407.30 \mathrm{~cm}^{-1}$. The broad and intense absorption spectrum at around 3215.54 corresponds to the $\mathrm{O}-\mathrm{H}$ stretching vibrations of phenols and carboxylic acids. The shift from 3268.26 (leaf extract) to $3215.54 \mathrm{~cm}^{-1}$ (silver nanoparticles) may indicate the involvement of the $\mathrm{O}-\mathrm{H}$ functional group in the synthesis of the silver nanoparticles (Jancy and Inbathamizh, 2012). The FTIR spectrum showed a band at 1567.76 (leaf extract) and $1528.24 \mathrm{~cm}^{-1}$ (silver nanoparticles) which corresponds to the bending vibration of the amide bands of the proteins (Navin et al., 2010). The peak at $1397.61 \mathrm{~cm}^{-1}$ (leaf extract) shows the $\mathrm{C}-\mathrm{N}$ stretching vibrations of the aromatic amines and the shift of this band to $1278.51 \mathrm{~cm}$ ${ }^{1}$ (silver nanoparticles) may predict the involvement of the aromatic amines in the synthesis of silver nanoparticles (Baishya and Kalita, 2013). The spectrum also shows a peak at $1043.23 \mathrm{~cm}^{-1}$ (leaf extract) which corresponds to aliphatic amines and the shift of this peak to 1023.90 (silver nanoparticles) shows the involvement of amines in the formation of silver nanoparticles (Navin et al., 2010). The peaks at 535.52 and $407.30 \mathrm{~cm}^{-1}$ corresponds to alkyl halide and hydroxyl groups, respectively (Preetha et 


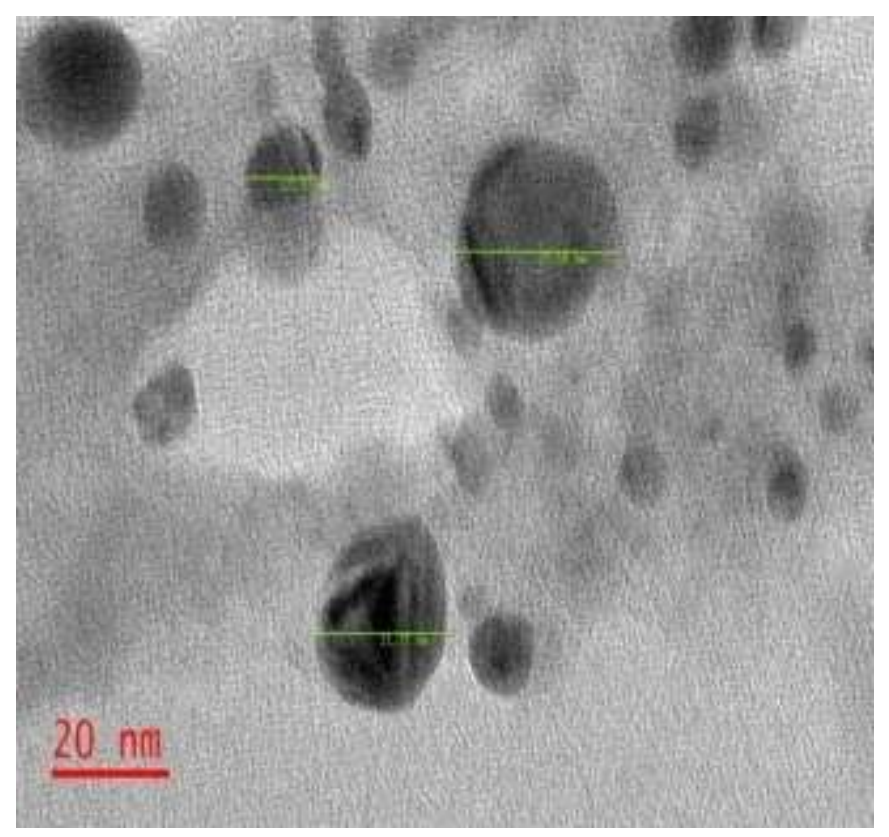

Figure 7. TEM images of silver nanoparticles at $\mathrm{pH} 4$ scanned at $20 \mathrm{~nm}$.

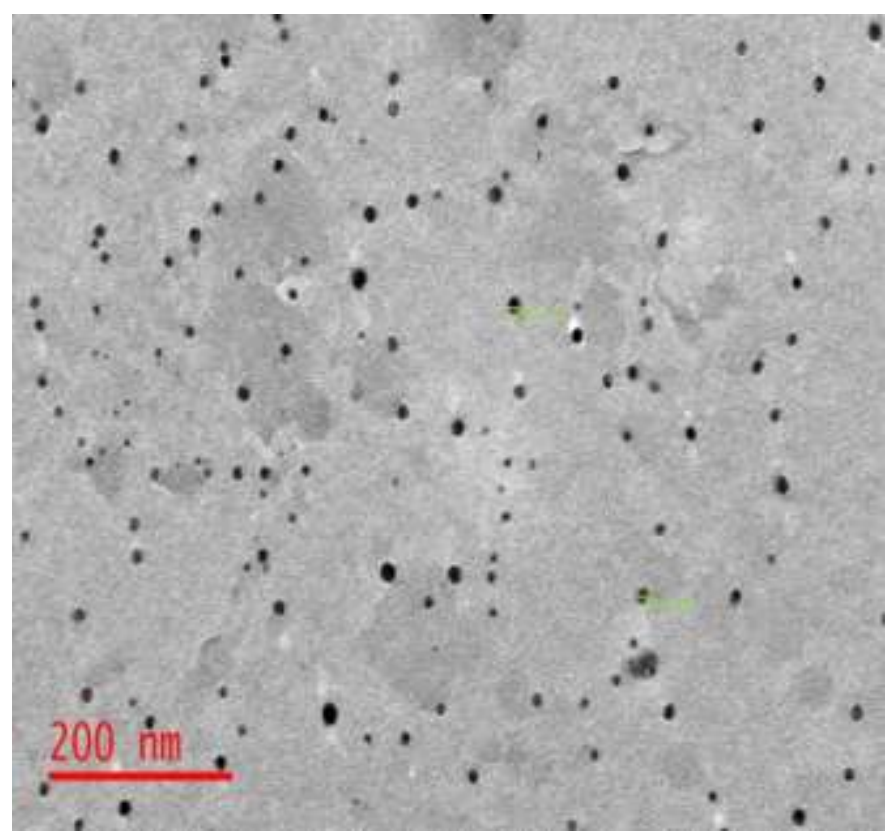

Figure 8. TEM images of silver nanoparticles at $\mathrm{pH} 7$ scanned at $200 \mathrm{~nm}$.

al., 2014). The shifting of the peak from $407.40 \mathrm{~cm}^{-1}$ (leaf extract) to $407.05 \mathrm{~cm}^{-1}$ (silver nanoparticles) indicates the bonding between the silver nanoparticles and the oxygen on the hydroxyl groups (Kokila et al., 2015). The shift of band position in the spectra of silver nanoparticles as compared to the spectra of the leaf extract suggest that

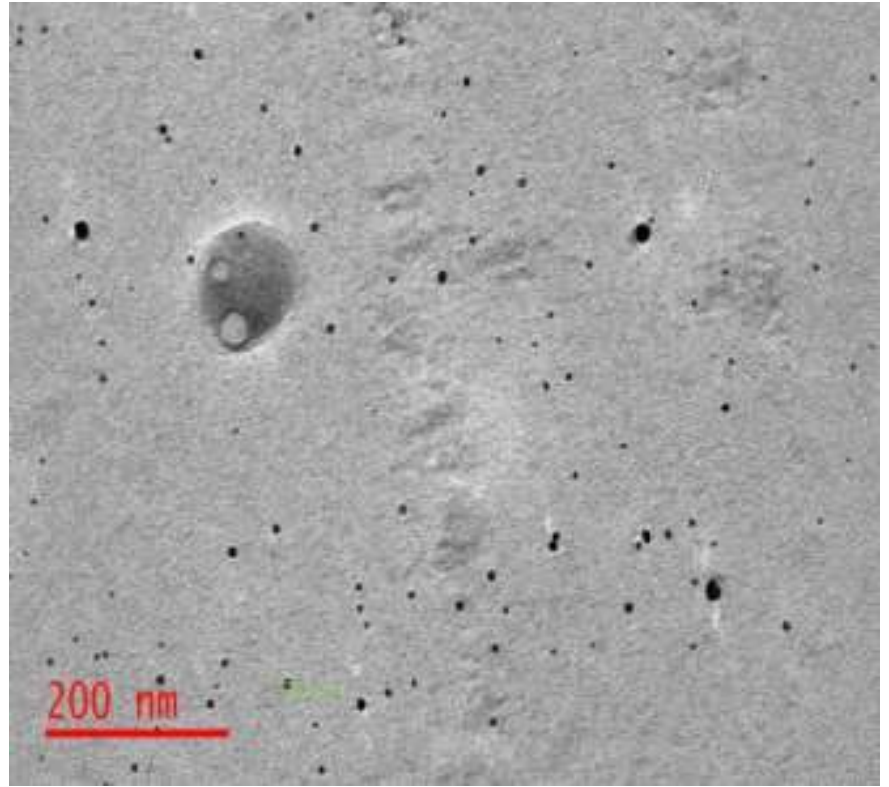

Figure 9. TEM images of silver nanoparticles at $\mathrm{pH} 11$ scanned at $200 \mathrm{~nm}$.

the above mentioned functional groups maybe involved in the reduction of silver ions as well as the stabilization of the nanoparticles. Studies have shown that the $C$. anguria leaf extract contains phenolic compounds, flavonoids, terpenoids, saponins and some other proteins which can cause the reduction of metal ions and the stabilization of the synthesized silver nanoparticles (Shankar et al., 2004; Chandran et al., 2006).

\section{Transmission electron microscopy analysis}

The TEM images of the silver nanoparticles synthesized at $\mathrm{pH} 4,7$ and 11 are shown in Figures 7 to 9, respectively.

The average size of the silver nanoparticles at $\mathrm{pH} 4$ is around $20.64 \mathrm{~nm}$, the average size of nanoparticles at $\mathrm{pH}$ 7 is around $13.51 \mathrm{~nm}$ and the average size for nanoparticles at $\mathrm{pH} 11$ is around $11.01 \mathrm{~nm}$. Lower $\mathrm{pH}$ values for example $\mathrm{pH} 4$ promote the nucleation of the silver nanoparticles leading to the formation of larger nanoparticles (Kokila et al., 2015). High pH values cause electrostatic repulsions among the nanoparticles thereby leading to the formation of smaller and highly dispersed nanoparticles (Sathishkumar et al., 2009). TEM results also show that the nanoparticles synthesized are spherical in nature and this agrees well with the UV-Vis results which produced a single peak depicting the formation of spherical nanoparticles according to Mies theory (Kokila et al., 2015). Similar results were obtained when silver nanoparticles were synthesized using $C$. sativus fruit extract (Roy et al., 2015). 


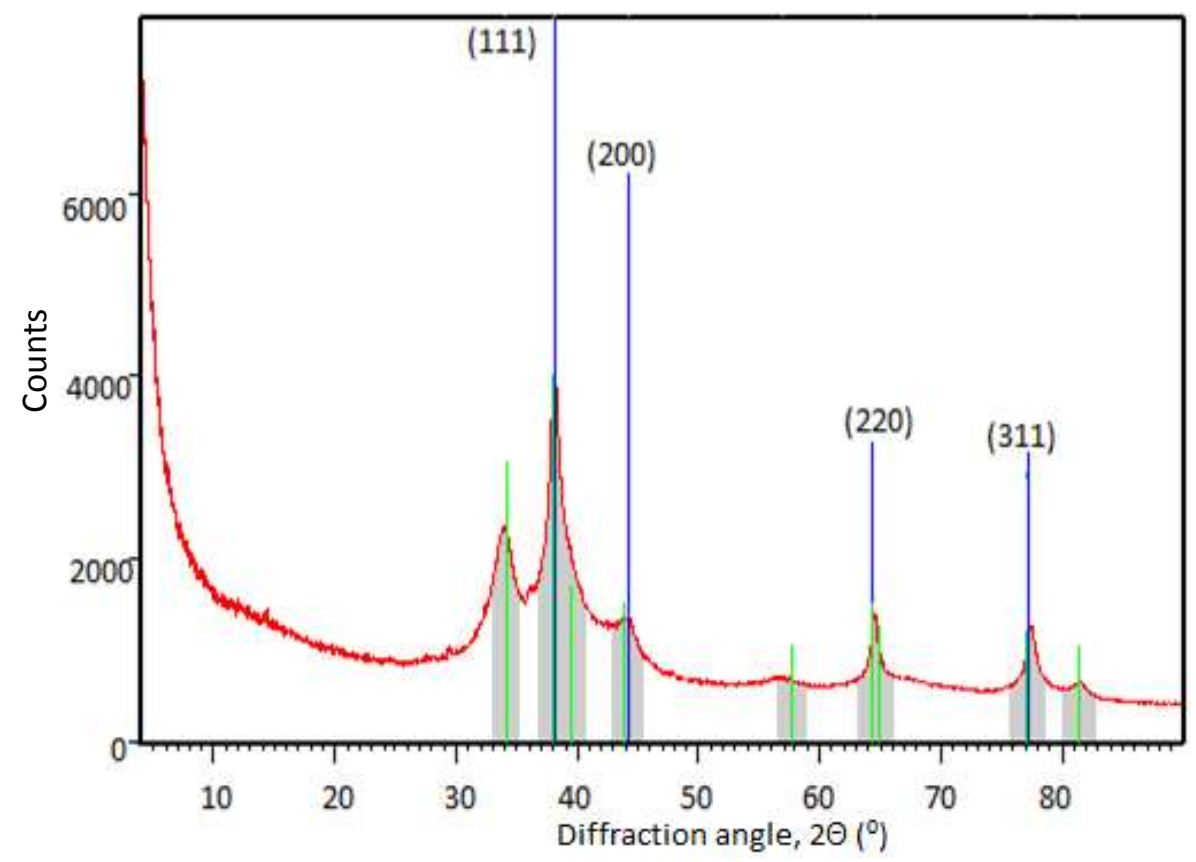

Figure 10. XRD diffractogram showing the intensity of peaks as a function of diffraction angles.

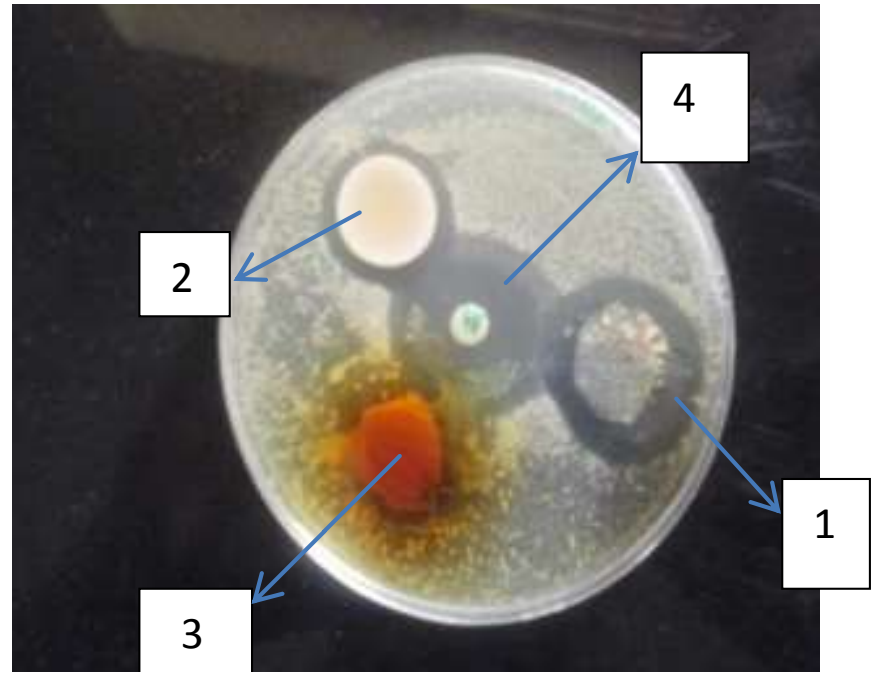

Figure 11. The antibacterial activity of (1) $\mathrm{AgNPs}$, (2) $\mathrm{AgNO}_{3}$, (3) leaf extract and (4) Kanamycin against $S$. aureus.

\section{$X$-ray diffraction analysis}

XRD results are shown on Figure 10 with the main peaks at $38.1286,44.1242,64.5511$ and $77.4726^{\circ}$ corresponding to the $111,200,220$ and 311 planes, respectively. This indicatesthat the silver nanoparticles are spherical and crystalline in nature, Ibrahim (2015) with face centered cubic structure (FCC) according to data comparison with the 'data base of joint committee on
Powder Diffraction Standards (JCPDS) file No. 04-0783'. Apart from these peaks which arise due to silver nanoparticles, the recorded XRD diffractogram has additional peaks at 33.9693 and 56.8604 and 81.46 . This might be due to the formation of the crystalline bioorganic compounds/metallo-proteins that are present in the C. anguria leaf extract (Anandalakshmi et al., 2016). The peak corresponding to the 111 plane is more intense than the other planes and this suggests that the 111 plane is the most predominant orientation.

\section{Antibacterial activity of silver nanoparticles}

The antibacterial activity of the synthesized silver nanoparticles was studied against two bacterial strains, $S$. aureus and $E$. coli. The inhibition zones around the silver nanoparticles, silver nitrate and leaf extract disks on both bacterial strains was noted and measured after $24 \mathrm{~h}$ of incubation at $37^{\circ} \mathrm{C}$. The synthesized silver nanoparticles proved to possess enhanced antibacterial activity against both S. aureus and E. coli, as clearly demonstrated by the clear zone of inhibition produced in Figures 11 and 12.

Also, the $C$. anguria leaf extract exhibited poor antibacterial activity when applied alone but there was an improved zone of clearance in combination with AgNPs. This shows the need for stabilization of AgNPs with leaf extract compounds. The lower antibacterial activity of the leaf extract could be due to its medium of extraction as well as due to lower concentration during experimentation. 


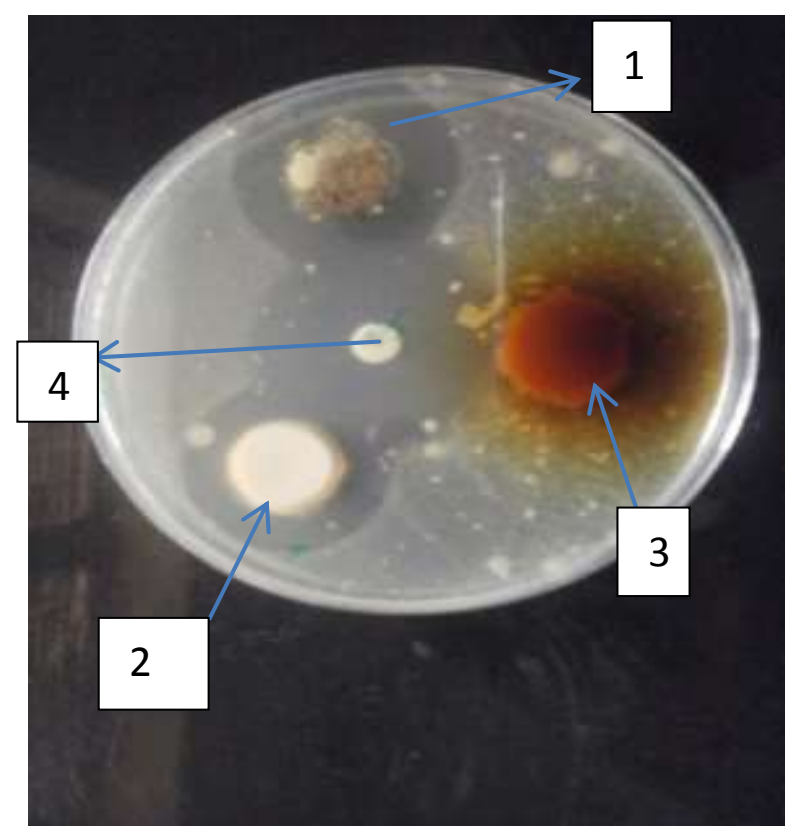

Figure 12. The antibacterial activity of (1) AgNPs, (2) $\mathrm{AgNO}_{3}$, (3) leaf extract and (4) Kanamycin against E. coli.

Table 1. The antibacterial activity of $\mathrm{AgNPs}, \mathrm{AgNO}_{3}$, C. anguria leaf extract and reference drug against $S$. aureus and E. coli.

\begin{tabular}{lcccc}
\hline \multirow{2}{*}{ Name of bacterial species } & \multicolumn{4}{c}{ Zone of inhibition (mm) } \\
\cline { 2 - 5 } & AgNPs & AgNO $_{3}$ & Leaf extract & Kanamycin \\
\hline S. aureus (Gram-positive) & 11 & 7 & 2 & 15 \\
E. coli (Gram-negative) & 13 & 9 & 4 & 15 \\
\hline
\end{tabular}

Thus, protocols for enhancing extracted concentration levels should be developed. The results of the antibacterial activity of the synthesized silver nanoparticles evaluated from the disc diffusion method are shown in Table 1.

The results obtained show that silver nanoparticles have a potential antimicrobial activity against both Grampositive and Gram-negative bacteria which are comparable with both silver nitrate and the standard drug (kanamycin).

It can be noted from the results that the diameter of the inhibition zone is higher for the Gram-negative bacteria (E. coli) than the Gram-positive bacteria (S. aureus). This slight difference can exist as a result of the differences in the composition of their cell wall. Gram-negative bacteria cell membrane comprises of a single layer of peptidoglycan whereas Gram-positive bacteria cell membrane comprises of multi-layers of peptidoglycan that makes it more rigid for penetration (Roy et al., 2015). The bacterial cell wall is believed to possess small negative charge and as a result attract the silver cations from nanoparticles when they come closer to the bacterial cell wall. When $\mathrm{Ag}^{+}$ions experience some electrostatic attraction towards the bacterial cell wall, they move towards the cell wall and get attached to it and this leads to a change in the composition of the cell wall there by affecting its permeability (Ahmed et al., 2016). It is known that upon treatment with $\mathrm{Ag}^{+}$ions the microorganism DNA loses its replication ability and the expression of ribosome subunit proteins as well as other cellular proteins and enzymes essential to ATP production becomes inactivated. The antibacterial effect of the synthesized silver nanoparticles can be conferred by their extremely small size and their increased surface area through which they destroy the cell membrane, enter the microbe and cause intracellular damage (Franci et al., 2015).

\section{Conclusion}

The results of the present study suggest that $C$. anguria leaf extract can be used to synthesize silver nanoparticles with enhanced antibacterial activity which 
makes them a potential source of antibacterial agent against $S$. aureus and $E$. coli. The synthesized silver nanoparticles were found to be spherical in shape, crystalline and face centered with an average diameter of between 11.01 and $27.0 \mathrm{~nm}$. Formation time, $\mathrm{pH}$ and concentration of leaf extract were found to affect the formation of silver nanoparticles. An increase in $\mathrm{pH}$ was found to enhance nanoparticle formation and the optimum $\mathrm{pH}$ for formation of silver nanoparticles was $\mathrm{pH}$ 11. Maximum formation time for synthesis of silver nanoparticles was $48 \mathrm{~h}$. The synthesis of silver nanoparticles enhances the therapeutic efficacy and medicinal values of $C$. anguria. Hence the results are promising and they prove to be an important step in the direction of medicine as it decreases the burden of multidrug resistance. Characterization techniques such as UV-vis, FTIR, TEM and XRD strongly suggest the synthesis of silver nanoparticles and the disc diffusion method proved the antibacterial activity of the synthesized silver nanoparticles.

\section{CONFLICT OF INTERESTS}

The authors have not declared any conflict of interests.

\section{ACKNOWLEDGEMENT}

The authors would like to thank Bindura University research board for the partial financial assistance.

\section{REFERENCES}

Ahmed S, Ahmad M, Swami BL, Ikram S (2016). A review on plant extract mediated synthesis of silver nanoparticles for antimicrobial applications: A green expertise. J. Adv Res. 7(1):17-28.

Alexander $\mathrm{J}$ (2009). History of the medical use of silver. Surg. Infect. 10(3):289-292.

Anandalakshmi K, Venugobal J, Ramasamy V (2016). Characterization of silver nanoparticles by green synthesis method using Pedalium murex leaf extract and their antibacterial activity. Appl. Nanosci. 6(3):399-408.

Baishya B, Kalita MC (2013) Green synthesis of gold nanoparticles using Musa Balbisiana Bract extract. Int. Pharm. Bio Sci. 4(3):873881.

Chanda S (2014). Silver nanoparticles (medicinal plant mediated): a new generation of antimicrobials to combat microbial pathogens-a review. Microbial pathogens and strategies for combating them. Science Technology and Education: FORMATEX Research Center, Badajoz, Spain, pp. 1314-1323.

Chandran SPM, Pasricha R, Ahmad A, Sastry M (2006). Synthesis of gold nanoparticles and silver nanoparticles using Aloe vera plant extract. Biotechnol. Prog. 22(2):577-583.

Chen D, Qiao X, Xiu X, Chen J (2009). Synthesis and electrical properties of uniform silver nanoparticles for electronic applications. J. Mater. Sci. 44(4):1076-1081.

Devara P, Kumari P, Aarti C, Renganathan A (2013). Synthesis and characterization of silver nanoparticles using Cannon ball leaves and their Cytotoxic activity against McF-7 cell line. J. Nanotechnol. 2013:1-5.

Duncan TV (2011). Applications of nanotechnology in food packaging and food safety; barrier materials, antimicrobials and sensors. $J$
Colloid Interface Sci. 363:1-24

Dzomba P, Mupa M (2012). Wild Cucumis anguria leaves: phytochemical profile and antioxidant capacity. Asian Pa. J. Trop Biomed. 1-5.

Franci G, Falang A, Galdiero S, Palomba L, Rai M, Morell G, Galderio $M(2015)$. Silver nanoparticles as potential antibacterial agents. Molecules 20(5):8856-8874.

Gong P, Li H, He X, Wang K, Hu J, Tan W (2007). Preparation and antibacterial activity of silver nanoparticles. Nanotechnology 18:604611.

Gopinath V, Ali MD, Priyadarshin S, Meerapriyadharsshin N, Thajuddin $\mathrm{N}$, Velusamy $\mathrm{N}$ (2012). Biosynthesis of silver nanoparticles from Tribulusterrestris and its antimicrobial activity: A novel biological approach. Colloid Surf. B Bio Interface 96:69-74

He R, Qian M, Yin J (2002). Preparation of polychrome silver nanoparticles in different solvents. J. Mater. Chem. 12:3783-3786.

Ibrahim HM (2015). Green synthesis and characterization of silver nanoparticles using banana peel extract and their antimicrobial activity against representative microorganisms. J. Radiat. Res. Appl. Sci. 8(3):265-275

Iravani S (2011). Green Synthesis of metal nanoparticles using plants. Green Chem. 13(10):2638-2650.

Jacob JA, Biswas N, Mukherjee T, Kapoor S (2011). Effect of plant based phenol derivatives on the formation of copper and silver nanoparticles. Colloids Surf. B 87:49-53.

Jancy ME, Inbathamizh L (2012). Green synthesis and characterization of nano silver using leaf extract of Morinda. Pubescens Asian $\mathrm{J}$ Pharm. Clin. Res. 5:159-162.

Jeong SH, Yeo SY, Yi SC (2005).The effect of filter particle size on the antibacterial properties of compounded polymer/silver fibres. J. Mater. Sci. 40:5407-5411.

Jha A, Prasad K, Kulkarni AR (2009). Plant system natures' nanofactory. Colloids Surf. B 73:219-223.

Kokila T, Ramesh PS, Geetha A (2015). Biosynthesis of silver nanoparticles from Cavendish banana peel extract and its antibacterial and free radical Scavenging assay: A novel biological approach. Appl. Nanosci. 5:911-920.

Kumar S, Singh M, Halder D, Mitra A (2015). Lippia javanica: A cheap natural source for the synthesis of antibacterial silver nanocolloid. Appl. Nanosci. 6:2-7.

Kumarasamyraja D, Jeganathan NS (2013). Green synthesis of silver nanoparticles using aqueous extract of acalyphaindica and its antimicrobial activity. Int. J. Pharm Bio Sci. 4(3):469-476.

Lee KS, El-Sayed MA (2006). Gold and silver nanoparticles in sensing imaging: Sensitivity of plasmom response to size, shape and metal composition. J. Phys. Chem. B 110:19220-19225.

Malabadi RB, Mulgund GS, Nataraga K (2005). Screening of antibacterial activity in the extracts of clitoriaternatha (Linn). J. Med. Aromat. Plant Sci. 27:26-29.

Maria BS, Devadiga A, Kidialbail VS, Saidutta MB (2015). Synthesis of silver nanoparticles using medicinal Zizyphusxylopyrus bark extract. Appl. Nanosci. 5(6):755-762.

Martinez-Castanon GA, Nino-Martnez N, Martinez-Gutierres $F$, Martinez-Mendoza JR (2008). Synthesis and antibacterial activity of silver nanoparticles with different sizes. J. Nanopart. Res. 10:13431348

Moon KS, Dong H, Maricco R, Pothukuchi S, Hunt A, Li Y, Wong P (2005). Thermal behavior of silver nanoparticles for low-temperature interconnect applications. J. Electron. Mater. 34(2):168-175.

Mukherjee P, Senepati S, Mandal D, Ahmed A, Khan MI, Kumer R, Sasty M (2002). Extracellular synthesis of gold nanoparticles by the fungus Fusarim oxyporum. Biochem. ChemBioChem. 3(5):461-3.

Nagarajan R (2008). Nanoparticles: Synthesis, stabilization, passivation and functionalization. Am. Chem. Soc. 1:13.

Narayanan R (2012). Nanoparticles of different shapes for Biosensor applications: Functional Nanoparticles for Bioanalysis. Nanomed. Bioelectric Devices 1(10):281-292.

Navin J, Arpit B, Sonali MJC, Tarafdarb T, Jitendra P (2010). Extra cellular biosynthesis and characterization of silver nanoparticles using Aspergillus flavus: A mechanism perspective. J. R. Soc. Chem. 3:635-641.

Oza G, Pandey S, Shah R, Sharon M (2013). Extracellular fabrication of 
silver nanoparticles using Pseidomanasaeniginosa and its antimicrobial assay. Adv. Appl. Sci. Res. 3:1776-1783.

Prasad KS, Darshit P, Ankita P, Palak D, Prasad R, Pradeep P, Selvarajan K (2011). Biogenic syntheses of silver nanoparticles using NicotinaTobbaccum of leaf extract and study of their antibacterial effect. Afr. J. Biotechnol. 10(41):8122-8130.

Preetha D, Renganathan A, Chirom A, Prachi K (2014) Synthesis and characterization of silver nanoparticles using Tabernaemontana Divaricata and its cytotoxic activity against MCF-7 cell line. Int. J. Pharm. Pharm. Sci. 6(8):86-90.

Raghunandan D, Bedre MD, Basavaraja S, Sawles B, Manjunath S, Venkataraman S, (2010). Rapid synthesis of irregular shaped gold nanoparticles from macerated aqueous extracellular dried clove buds (Syzygium aromaticum) solution. Colloids Surf. B Biointerfaces 79(1):235-240.

Rodriguez-Leon E, Palomares L, Navaroo RE, Herrera-Urbina R, Tanori J, Inguez-Palomare C, Maldonado A (2013). Synthesis of silver nanoparticles using reducing agents obtained from natural sources (Rumex hymenosepalus extracts). Nanoscale Res. Lett. 8:318-326.

Roy K, Sarkar CK, Ghosh CK (2015). Single step novel biosynthesis of silver nanoparticles using Cucumis sativus fruit extract and study of its photocatalytic and antibacterial activity. Dig. J. Nanomater. Biostruct. 10(1):107-115.

Roy S, Das TK (2015). Plant mediated Green synthesis of silver nanoparticles: A Review. Int. J. Plant Biol. Res. 3(3):1044.

Sathishkumar M, Sneha K, Won SW, Cho CW, Yun YS (2009). Cinamonzeylanicum bark extract and powder mediated green synthesis of nano crystalline silver particles and its bacterial activity. Colloids Surf. B Biointerfaces 73:332-338.
Saware K, Sawle B, Salimath B, Jayanth K, Abbaraju V (2014). Biosynthesis and characterization of silver nanoparticles using $F$ Benghalensis leaf extract. Int. J. Res. Eng. Technol. 3(5):867-874.

Shahverdi AR, Fakhimi A, Shahverdi HR, Minaian S (2007). Synthesis and effect of silver nanoparticles on the antibacterial activity of different antibiotics against Staphylococcus aureus and Escherichia coli. Nanomedicine 3:168-171.

Shankar SS, Rai A, Ahmad A, Sastry M (2004). Rapid synthesis of gold, silver and bimetallic gold core-silver shell nanoparticles using Neem leaf broth. J. Colloid Interface Sci. 275:496-502.

Singh K, Panghal M, Kadyan S, Chaudhary U, Yadv JP (2014). Antibacterial activity of silver nanoparticles from Tinospora cordifolia against multidrug resistant strains of Pseudomonas auruginosa isolated from burn patients. J. Nanomed. Nanotechnol. 5:2-7.

Suman TY, Rajasree SR, Elizabeth SB, Kanchana A (2013). Biosynthesis, characterization and cytotoxic effect of plant mediated silver nanoparticles using Morinda citrifolia root extract. Colloids Surf. B 10:74-78.

Sun Q, Xiang C, Jiangwei L, Zheng M, Chen Z, Chang-Ping Y (2014). Green synthesis of silver nanoparticles using tea leaf extract and evaluation of their stability and antibacterial activity. Colloids Surf. A Physicochem. Eng. Asp. 444:226-223.

Xu ZP, Lu GQ, Yu AB (2006). Inorganic Nanoparticles As For Efficient Cellular Delivery. Chem. Eng. Sci. 61:334-337.

Zayed MF, Eisa WH, Shabaka AA (2012). Malva parviflora extract assisted green synthesis of silver nanoparticles. Spectrochim. Acta A Mol. Biomol. Spectrosc. 98:423-428. 